Marquette University

e-Publications@Marquette

School of Dentistry Faculty Research and

Publications

Dentistry, School of

$1-1-2015$

\title{
Developing Student, Family, and School Constructs From NLTS2 Data
}

Karrie A. Shogren

University of Kansas

Mauricio Garnier-Villarreal

Marquette University, mauricio.garniervillarreal@marquette.edu

Accepted version. Journal of Special Education, Vol. 49, No. 2 (2015): 89-103. DOI.C 2015 SAGE

Publications. Used with permission. 


\section{Marquette University}

\section{e-Publications@Marquette}

\section{Nursing Faculty Research and Publications/College of Nursing}

This paper is NOT THE PUBLISHED VERSION; but the author's final, peer-reviewed manuscript. The published version may be accessed by following the link in the citation below.

Journal of Special Education, Vol. 49, No. 2 (2015): 89-103. DOI. This article is C SAGE Publications and permission has been granted for this version to appear in e-Publications@Marquette. SAGE Publications does not grant permission for this article to be further copied/distributed or hosted elsewhere without the express permission from SAGE Publications.

\section{Developing Student, Family, and School Constructs From NLTS2 Data}

Karrie A. Shogren

University of Kansas, Lawrence, KS

Mauricio Garnier Villarreal

University of Kansas, Lawrence, KS

\section{Abstract}

The purpose of this study was to use data from the National Longitudinal Transition Study-2 (NLTS2) to (a) conceptually identify and empirically establish student, family, and school constructs; (b) explore the degree to which the constructs can be measured equivalently across disability groups; and (c) examine latent differences (means, variances, and correlations) in the constructs across disability groups. Conceptual analysis of NLTS2 individual survey items yielded 21 student, family, and school constructs, and 16 were empirically supported. Partial strong metric invariance was established across disability groups, and in the latent space, a complex pattern of mean and variance differences across disability groups was found. Disability group moderated the correlational relationships between multiple predictor constructs, suggesting the key role of disability-related characteristics in 
understanding the experiences of youth with disabilities. Implications for future research and practice are discussed.

\section{Keywords}

$\underline{\text { self-determination, transition, contextual factors, structural equation modeling (SEM) }}$

Researchers increasingly acknowledge the impact of contextual factors on the experiences and outcomes of youth with disabilities. Two related movements, the adoption of a socialecological model of disability (Schalock et al., 2010; World Health Organization, 2007) and the application of the tenets of implementation science to the field of special education (Cook \& Odom, 2013), have brought increased attention to the impact that context has on (a) the experiences of youth with disabilities and (b) the implementation and impact of interventions to promote valued educational outcomes. However, despite the attention directed to contextual factors, defining context remains vexing. Shogren, Luckasson, and Schalock (in press), in a review of the literature on context and intellectual disability, identified more than 70,000 articles, with the majority published in the past 10 years, that used the term context, but found no consistent definition. Researchers used context to refer to both independent (or moderating) variables that were typically not directly manipulated but had a relationship with outcomes (e.g., disability label) as well as intervening (or mediating) variables that could be directly manipulated to affect outcomes (e.g., school polices or family practices; Shogren, Luckasson, et al., in press).

One of the most difficult aspects of fully exploring the influence of contextual factors is identifying, cataloguing, and examining the impact of a diverse array of relevant contextual factors (Shogren, in press). Such work is necessary, however, to build a comprehensive understanding of the diversity of student, family, and school factors that influence student experiences and outcomes. The traditional approach in research has been to study a narrow range of factors, typically at one level of the ecological system (e.g., personal characteristics such as gender or disability label), rather than attempting to identify and explore factors across ecological systems (Bronfenbrenner, 2005). And, perhaps related to the lack of focus on systematically exploring contextual factors in research, there has also been limited assessment and integration in practice of a comprehensive understanding of contextual factors in designing systems of supports to improve youth experiences and outcomes.

The availability of data from the National Longitudinal Transition Study-2 (NLTS2) provides researchers with access to a large, nationally representative data set with extensive information on student's secondary and post-school experiences and, potentially, the opportunity to define and explore contextual factors that might affect youth's secondary experiences and outcomes. Although a tremendous amount of information was collected under NLTS2, nearly all the data was comprised of individual survey items rather than scales with established reliability and validity. Researchers interested in examining the complex pattern of relationships between student, family, and school factors, therefore, must identify conceptually related survey items using a strong theoretical basis and investigate measurement properties using analytical approaches, such as structural equation modeling (SEM; Little, 2013) that allow the integration of measurement models, which specify the relationships among latent and 
observed variables, with structural models, which specify the relationship between latent factors.

The purpose of this study was to use data from NLTS2 to develop and test student, family, and school factors to examine the measurement of contextual factors in youth with disabilities. Such work has the potential to promote the systematic consideration of contextual factors when designing systems of supports. Relatedly, we were interested in examining the influence of disability label on contextual factors. There were three primary research questions:

- Research Question 1: Can latent student, family, and school constructs be generated from NLTS2?

- Research Question 2: Can the latent constructs be measured equivalently across disability groups?

- Research Question 3: Are there differences in the latent means, variances, and correlations across disability groups?

\section{Method}

\section{Sample}

The NLTS2 was a federally funded study to explore the secondary and post-school experiences of students with disabilities. Data were collected over a 10-year period (20002010) in five waves by SRI International. The NLTS2 sampling plan was designed to generalize to the population of students receiving special education services in the United States in each of the 12 federally recognized disability categories at the secondary level. Approximately 1,250 students per disability category were sampled in Wave 1, which was projected to lead to a sufficient sample in Wave 5 of data collection (SRI International, 2000). The present analyses are part of a larger project to build social-ecological models of contextual factors that may affect self-determination and other post-school outcomes. Therefore, the NLTS2 data used for the analyses were confined to those students for whom selfdetermination data were available. This represented approximately $83 \%$ of the overall NLTS2 student sample (see Shogren, Kennedy, Dowsett, \& Little, in press, for more information). Data on student self-determination were collected once during the NLTS2 Direct Student Assessment during Wave 1 (Years 1 and 2) or Wave 2 (Years 3 and 4), depending on the age of the student (students in older age cohorts were sampled in Wave 1 and in younger age cohorts in Wave 2; SRI International, 2000).

\section{Procedure}

To define and empirically examine contextual factors measured in NLTS2, we first generated a conceptual list of student, family, and school factors by reviewing the literature on contextual factors that affect transition outcomes, including self-determination, using a social-ecological perspective (Shogren, in press). Next, using data dictionaries for each NLTS2 data collection instrument created by SRI International, the research team used a systematic process to select NLTS2 variables to develop student, family, and school constructs. Each NLTS2 variable described in the NLTS2 data dictionaries was independently reviewed by two 
members of the research team and linked with appropriate contextual factors. New factors were added as they emerged from the NLTS2 variables. We primarily used data collected during Wave 1 of NLTS2. The only exception was the Student Direct Assessment, which was collected in Wave 1 or 2 (SRI International, 2000). Individual survey items were used from six NLTS2 data collection instruments in Wave 1: Parent Telephone Interview, Direct Student Assessment, School Characteristics Survey, School Program Survey, Teacher Survey, and Transcript Records. Further information and examples of instruments can be found at http://www.nlts2.org/studymeth/\#data collection.

The list of student, family, and school constructs and their associated NLTS2 variables were then reviewed with two researchers associated with NLTS2 design, data collection, and management. This process yielded 21 potential constructs: 8 student constructs, 5 family constructs, and 8 school constructs. Across the 21 constructs, more than 270 variables from the NLTS2 data set were used, with each construct having between 3 and 27 NLTS2 variables. Table 1 provides a brief overview of the initial conceptual constructs. Several constructs (e.g., functional skills, home independence, parent involvement, access to the general curriculum) had subdomains. The 21 constructs and their subdomains were then subjected to empirical analysis.

\begin{tabular}{|c|c|c|}
\hline Student constructs & Family constructs & School constructs \\
\hline Academic skills & Home independence & Access to the general education curriculum \\
\hline $\begin{array}{l}\text { Classroom performance (2) } \\
\text { Direct assessment of academic skills (6) } \\
\text { Grades (3) }\end{array}$ & $\begin{array}{l}\text { Financial responsibilities (4) } \\
\text { Household responsibilities (4) } \\
\text { Life skills at home (7) } \\
\text { Social skills at home (12) }\end{array}$ & $\begin{array}{l}\text { Academic curriculum (5) } \\
\text { Accommodations and modifications (4) }\end{array}$ \\
\hline $\begin{array}{l}\text { Classreom behavior } \\
\text { Vocational classes ( } 9 \text { ) } \\
\text { General education classes ( } 9 \text { ) } \\
\text { Special education classes (9) }\end{array}$ & $\begin{array}{l}\text { Opportunities for self-determination at } \\
\text { home" } \\
\text { Life skills opportunities (4) } \\
\text { Social skills opportunities (5) }\end{array}$ & Inclusion (9) \\
\hline Communication skills (4) & $\begin{array}{l}\text { Parent inwolvement } \\
\text { General (7) } \\
\text { Special education (5) } \\
\text { Transition planning (3) }\end{array}$ & $\begin{array}{l}\text { School climate } \\
\text { Expectations (5) } \\
\text { Family supports (7) } \\
\text { Safety (4) } \\
\text { Student supports (4) } \\
\text { Teacher supports (7) }\end{array}$ \\
\hline $\begin{array}{l}\text { Functional skills } \\
\text { Community living skills (1) } \\
\text { Mental skills (4) } \\
\text { Daily living skills (2) }\end{array}$ & Parent outcome expectations (10) & $\begin{array}{l}\text { Social networks } \\
\text { In school (4) } \\
\text { Out of school (7) }\end{array}$ \\
\hline $\begin{array}{l}\text { Self-concept (15) } \\
\text { Social skills (17) } \\
\text { Well being }(8)^{2} \\
\text { Work experience }(3)^{*}\end{array}$ & $\begin{array}{l}\text { Parent perception of school experience } \\
(12)^{2}\end{array}$ & $\begin{array}{l}\text { Supports } \\
\text { In school (4) } \\
\text { Out of school (7) } \\
\text { Student imvolvement in transition planning (12) } \\
\text { Teacher expectations (3) } \\
\text { Vecational experiences (17) }\end{array}$ \\
\hline
\end{tabular}

"Indicates conceptual construct that was dropped completely from fnal empirical model because of poor model fic.

\section{Data Analysis}

\section{Research Question 1}

After the conceptual constructs were generated, they were tested to determine whether they were empirically viable (i.e., did the identified NLTS2 items for each construct hang together). Mplus, version 6.12 (Muthén \& Muthén, 1998-2010), with the "type=complex" option and the "wt_na" sampling weight, stratum, and cluster variables for the complex sampling design was 
used for all analyses. Each construct and its subdomains, when relevant, were subjected to confirmatory factor analysis (CFA). Individual CFAs were used so that issues within each construct could be identified and a determination made as to whether the data justified the creation of a latent construct. We first examined the reliability of the factor loadings of each NLTS2 item for each construct. Factor loadings indicate how much variance is shared between the indicators, and the shared variance between indicators defines the latent constructs (Little, 2013); therefore, we only kept indicators with high factor loadings (more than .4) that were significant for all disability groups. After identifying the best indicators for each construct, we then evaluated overall model fit, seeking a root mean square error of approximation (RMSEA) of less than .08, and a non-normed fit index (NNFI) and comparative fit index (CFI) criterion of .85 (Little, 2013), which is slightly lower than typically used because of low correlations among indicators in the NLTS2 data resulting from the lack of scales with established reliability and validity (Taylor, 2008). During this process, because a number of NLTS2 variables did not show significant loadings on constructs or failed to hang together to form a construct, the 21 conceptual constructs were significantly reduced and modified.

After good model fit was established, because of the large number of possible NLTS2 variables that could contribute to each construct, parcels were created using theoretical or empirical aggregation for constructs that had greater than six indicators that demonstrated good psychometric properties to promote parsimony while keeping information from the indicators (Little, 2013; Little, Rhemtulla, Gibson, \& Schoemann, 2013).

Research Question 2

After empirically determining which conceptual constructs were (and were not) supported by empirical analysis, we then examined measurement invariance of the empirically supported constructs across disability groups in an overall model. It is important to note that the overall model also included three self-determination constructs (autonomy, self-realization, psychological empowerment) established in previous research (Shogren, Kennedy, et al., in press), because the models developed for the present analyses will be used in future work to examine the degree to which contextual factors predict self-determination. The selfdetermination constructs were used as "placeholders" to allow for these future research activities, but were not pertinent to the present analyses, and are not described in the results.

We used SEM, specifically multiple-group confirmatory factor analysis (CFA) based on the Means and Covariance Structures (MACS) model (Little, 1997). Examining measurement invariance allows researchers to conclude that the same constructs are being measured across groups; establishing the same items (i.e., NLTS2 variables) can be used to define the construct in diverse groups (Little, 1997). Because of number of constructs to estimate and the diverse disability groups represented in the NLTS2 data set, previous work (Shogren, Kennedy, et al., in press) was used to guide the creation of disability groups for invariance testing. Shogren, Kennedy, et al., in examining self-determination constructs, found that the 12 disability groups represented in the NLTS2 data could be collapsed into six groups. The groups consisted of students with high-incidence disabilities (HIN; learning disabilities, emotional disturbances, speech or language impairments, and other health impairments), sensory disabilities (SEN; visual and hearing impairments), and cognitive disabilities (COG; 
autism, multiple disabilities, and deaf-blindness). Students with intellectual disability (INT), traumatic brain injury (TBI), and orthopedic impairments (ORT) could not be collapsed.

Measurement invariance was tested in three steps. First, configural invariance was tested by constraining all groups to have the same pattern of fixed and free parameters. Second, the model was further constrained to test for weak factorial invariance by equating factor loadings across all groups. Third, strong metric invariance was tested by equating indicator means. We used a CFI difference of .01 or less between models (Cheung \& Rensvold, 2002) and whether the nested models fell within the 90\% confidence interval of the RMSEA of the previous model (Little, 2013) to confirm invariance with increasing constraints.

\section{Research Question 3}

After examining the measurement models to test invariance, we shifted to examining structural models to explore similarities and differences in the latent means, variances, and correlations of the constructs across the disability groups (Little, 1997). To explore the pattern of relationships in the constructs within and across disability groups, we performed a series of two-group contrasts using a $X^{2}$ model comparison between nested models (Little, 2013). For each test, the relevant latent parameter (latent mean, variance) was equated between two disability groups. To test the latent correlations we first performed an overall equality test, equating each correlation to be equal across all groups, then the correlations that showed a significant difference were compared between each pair of disability groups. A significant change in $x^{2}$ indicates that the latent parameter should be estimated separately for each group or that it differs across groups. Because of the extremely high number of parameters to compare (285 mean comparisons, 285 variance comparisons), we used a cutoff point of $p$ $<.005$.

\section{Results}

\section{Contextual Factors (Research Question 1)}

Of the initial 21 conceptual constructs (see Table 1), 16 met the criteria described in the Method section with regard to strong factor loadings and model fit, although it is important to note that to achieve this, the majority of constructs underwent significant revision, including the elimination of NLTS2 variables, and the merging, splitting, and reconceptualization of constructs. Table 2 provides a description of each of the empirically supported constructs, the NLTS2 data that led to the construct, and the key modifications made from the conceptual constructs initially developed. Each of the 16 constructs is robust, shows good model fit and strong factor loadings, and can be reliably estimated from the NLTS2 data. 
Table 2. 16 Empirically Verified Student, Family, and School Constructs, Brief Descriptions, and Modifications.

\begin{tabular}{|c|c|c|c|}
\hline Description of construct & & NLTS2 source and indicators & $\begin{array}{l}\text { Modifications from conceptual } \\
\text { (Table I) }\end{array}$ \\
\hline \multicolumn{4}{|l|}{ Student constructs } \\
\hline Grades $^{a}$ & $\begin{array}{l}\text { Student Grade Point Average } \\
\text { across multiple domains } \\
\text { (academic, vocational, other } \\
\text { classes) }\end{array}$ & $\begin{array}{l}\text { Ninth Grade Transcript } \\
\text { Data-ntgGPA_Acad; } \\
\text { ntgGPA_AnyV; ntgGPA_ } \\
\text { OthC (3 indicators) }\end{array}$ & $\begin{array}{l}\text { Only items related to grades } \\
\text { showed reasonable fit; direct } \\
\text { assessment and classroom } \\
\text { performance items showed poor } \\
\text { fit and were dropped leaving only } \\
\text { grades as latent construct }\end{array}$ \\
\hline Classroom behavior $^{a}$ & $\begin{array}{l}\text { Students behavior in vocational } \\
\text { classes (asking for what } \\
\text { needs; taking part in } \\
\text { discussions, staying focused) }\end{array}$ & $\begin{array}{l}\text { Wave I School Program } \\
\text { Survey-nprIC4[a-d]; } \\
\text { nprlc5[a-e]; (parcels of } 9 \\
\text { indicators) }\end{array}$ & $\begin{array}{l}\text { Only items related to vocational } \\
\text { classes showed reasonable fit, } \\
\text { items related to special and } \\
\text { general education classes were } \\
\text { dropped }\end{array}$ \\
\hline Functional skills $^{\mathrm{a}}$ & $\begin{array}{l}\text { Student performance of tasks } \\
\text { related to basic mental skills, } \\
\text { community living, and daily } \\
\text { living skills }\end{array}$ & $\begin{array}{l}\text { Wave I Parent Survey- } \\
\text { np I G3b; npI IG4a; npIG4e (3 } \\
\text { indicators) }\end{array}$ & $\begin{array}{l}\text { Several conceptually identified } \\
\text { items dropped from model } \\
\text { because of poor model fit }\end{array}$ \\
\hline Self-concept & $\begin{array}{l}\text { Self-confidence in academic and } \\
\text { social domains }\end{array}$ & $\begin{array}{l}\text { Direct Assessment- } \\
\text { ndaSC8a_[I-15] (parcels of } \\
15 \text { indicators from Student } \\
\text { Self-Concept Scale [SSCS]) }\end{array}$ & $\begin{array}{l}\text { N/A-Same as originally proposed } \\
\text { construct }\end{array}$ \\
\hline $\begin{array}{l}\text { Social and communication } \\
\text { skills }^{\mathrm{a}}\end{array}$ & $\begin{array}{l}\text { Student social interaction } \\
\text { (makes friends, interacts } \\
\text { socially, handles } \\
\text { disagreements) and } \\
\text { communication (speaks } \\
\text { clearly, carries on } \\
\text { conversation) skills }\end{array}$ & $\begin{array}{l}\text { Wave I Parent Survey- } \\
\text { npID[I0-II]; npI GI [a-k]; } \\
\text { npIAnylnteract, } \\
\text { npIFriendDate; np I B5[a-b], } \\
\text { [d-e] (parcels of 2I } \\
\text { indicators) }\end{array}$ & $\begin{array}{l}\text { Combined with proposed } \\
\text { communication skills construct } \\
\text { because of high correlations } \\
\text { between the constructs }\end{array}$ \\
\hline \multicolumn{4}{|l|}{ Family constructs } \\
\hline $\begin{array}{l}\text { General parent } \\
\text { involvement }^{\mathrm{a}}\end{array}$ & $\begin{array}{l}\text { Parent involvement in general } \\
\text { educational activities (school } \\
\text { meetings, class events, } \\
\text { volunteering, parent/teacher } \\
\text { conferences) and engagement } \\
\text { with youth (helps with } \\
\text { homework, talks about } \\
\text { experiences) }\end{array}$ & $\begin{array}{l}\text { Wave I Parent Survey and } \\
\text { Wave I Teacher Survey- } \\
\text { npIEI[a2-d2]; npeE[7- } \\
\text { 8], nts I C8 (parcels of } 7 \\
\text { indicators) }\end{array}$ & $\begin{array}{l}\text { Only items related to general } \\
\text { parent involvement demonstrated } \\
\text { reasonable fit, all items related } \\
\text { to parent involvement in the } \\
\text { Individualized Education Program } \\
\text { (IEP) or transition planning had } \\
\text { to be dropped. A single indicator } \\
\text { of parent involvement in special } \\
\text { education (SPED) planning was } \\
\text { created (below) }\end{array}$ \\
\hline Home independence $e^{a}$ & $\begin{array}{l}\text { Frequency that student does } \\
\text { household chores (fixing } \\
\text { meals, laundry, cleaning, } \\
\text { purchasing) }\end{array}$ & $\begin{array}{l}\text { Wave I Parent Survey- } \\
\text { npIG5[a-d] (4 indicators) }\end{array}$ & $\begin{array}{l}\text { Only items related to household } \\
\text { responsibilities showed adequate } \\
\text { model fit, all remaining indicators } \\
\text { dropped }\end{array}$ \\
\hline $\begin{array}{l}\text { Parent involvement } \\
\text { in special education } \\
\text { planning }\end{array}$ & $\begin{array}{l}\text { Parent attendance at most } \\
\text { recent IEP meeting }\end{array}$ & $\begin{array}{l}\text { Wave I Parent Survey- } \\
\text { npIE2a (single indicator } \\
\text { construct) }\end{array}$ & $\begin{array}{l}\text { A single indicator construct was } \\
\text { created despite item not fitting } \\
\text { in the overall parent involvement } \\
\text { construct or with the } 5 \\
\text { additional indicators identified for } \\
\text { involvement in SPED because of } \\
\text { cited importance in literature }\end{array}$ \\
\hline $\begin{array}{l}\text { Parent outcome } \\
\text { expectations }{ }^{\mathrm{a}}\end{array}$ & $\begin{array}{l}\text { Parent ratings of the likelihood } \\
\text { that student will achieve } \\
\text { valued adult outcomes } \\
\text { (graduation, postsecondary } \\
\text { education, getting a driver's } \\
\text { license, living away from } \\
\text { home, getting a job) }\end{array}$ & $\begin{array}{l}\text { Wave I Parent Survey- } \\
\text { npIJ[I-7],[9-10] (parcels of } 9 \\
\text { indicators) }\end{array}$ & $\begin{array}{l}\text { One conceptually identified } \\
\text { indicator demonstrated poor fit } \\
\text { and was dropped from model }\end{array}$ \\
\hline \multicolumn{4}{|l|}{ School constructs } \\
\hline $\begin{array}{l}\text { Access to the general } \\
\text { curriculum (academics) }\end{array}$ & $\begin{array}{l}\text { Access to core academic } \\
\text { subject areas }\end{array}$ & $\begin{array}{l}\text { Ninth Grade Transcript } \\
\text { Data_ntgHad_Eng; } \\
\text { ntgHad_Math; ntgHad_Sci (3 } \\
\text { indicators) }\end{array}$ & $\begin{array}{l}\text { Split from Accommodations and } \\
\text { Modifications because did not } \\
\text { fit with A\&M indicators; two } \\
\text { items related to participation in } \\
\text { standardized testing had to be } \\
\text { dropped because of poor fit }\end{array}$ \\
\hline $\begin{array}{l}\text { Access to the } \\
\text { general curriculum } \\
\text { (accommodations and } \\
\text { modifications) }\end{array}$ & $\begin{array}{l}\text { Access to classroom } \\
\text { accommodations and } \\
\text { modifications }\end{array}$ & 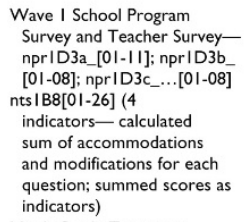 & $\begin{array}{l}\text { Split from Academics as } \\
\text { independent construct because } \\
\text { did not fit with indicators related } \\
\text { to academics }\end{array}$ \\
\hline Inclusion ${ }^{a}$ & $\begin{array}{l}\text { Percent of time in academics in } \\
\text { general education }\end{array}$ & $\begin{array}{l}\text { Ninth Grade Transcript } \\
\text { Data_ntgPctHrs_Acad_ } \\
\text { Gpl_ZF (single indicator } \\
\text { construct) }\end{array}$ & $\begin{array}{l}\text { Could not create a latent construct } \\
\text { with identified indicators ( }(9) \\
\text { because of fit issues; included a } \\
\text { single indicator construct because } \\
\text { of the importance of construct in } \\
\text { the literature }\end{array}$ \\
\hline Social networks ${ }^{a}$ & $\begin{array}{l}\text { Student participation in school } \\
\text { activities, social activities, } \\
\text { and volunteer/community } \\
\text { activities }\end{array}$ & 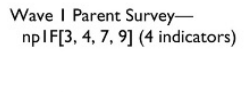 & $\begin{array}{l}\text { Several conceptually identified items } \\
\text { dropped because of poor model } \\
\text { fit, included items were from both } \\
\text { the in and out of school domains }\end{array}$ \\
\hline Supports ${ }^{a}$ & $\begin{array}{l}\text { Degree to which students } \\
\text { needs are being supported } \\
\text { emotionally and through } \\
\text { formal supports/services }\end{array}$ & $\begin{array}{l}\text { Wave I Parent Survey- } \\
\text { npIDI2[c-e]; npIH3 (4 } \\
\text { indicators) }\end{array}$ & $\begin{array}{l}\text { Several conceptually identified } \\
\text { items dropped because of poor } \\
\text { model fit, included items were } \\
\text { from both the in and out of } \\
\text { school domains }\end{array}$ \\
\hline $\begin{array}{l}\text { Student involvement in } \\
\text { educational planning }\end{array}$ & $\begin{array}{l}\text { Level of student participation } \\
\text { in transition planning }\end{array}$ & $\begin{array}{l}\text { Wave I School Program } \\
\text { Survey—npr IE9 (single } \\
\text { indicator construct) }\end{array}$ & $\begin{array}{l}\text { Could not create a latent construct } \\
\text { with identified indicators (12) } \\
\text { because of fit issues; included } \\
\text { a single indicator construct } \\
\text { because of the importance of this } \\
\text { construct in the literature }\end{array}$ \\
\hline$V$ ocational experiences ${ }^{a}$ & $\begin{array}{l}\text { Student access to vocational } \\
\text { goals, job development, and } \\
\text { work experiences }\end{array}$ & $\begin{array}{l}\text { Wave I Parent Survey and } \\
\text { School Program Survey- } \\
\text { nprICI4, nprID4_I0; 9th } \\
\text { Grade Transcript Data - } \\
\text { ntgVocScale (3 indicators) }\end{array}$ & $\begin{array}{l}\text { Several conceptually identified } \\
\text { items dropped from model } \\
\text { because of poor model fit }\end{array}$ \\
\hline
\end{tabular}

Note. NLTS2 = National Longitudinal Transition Study-2; GPA = Grade Point Average; N/A = not applicable.

Note. NLTS2 = National Longitudinal Transition Study-2; GPA $=$ Grade Point Average; N/A $=$ not applicable.
"Indicates construct that was significantly modified from original conceptual construct because of empirical analyses. 
The overall model that included all the empirically verified constructs as well as the selfdetermination constructs and disability as a grouping variable showed good fit to the data, $(x 2$ $(7572, \mathrm{n}=5240)=22138.9, \mathrm{RMSEA}=0.047(0.046,0.048), \mathrm{NNFI}=0.790, \mathrm{CFI}=0.821)$. When testing for measurement invariance across the six disability groups, as shown in Table 3 , we found that weak measurement invariance was supported (i.e., equating the loadings), but that strong metric invariance (i.e., equating the loadings and intercepts) was only partially supported. Follow-up testing suggested that indicator means could be constrained across the six groups, with three exceptions: One parcel from the parent outcome expectations construct needed to be freely estimated in the HIN group; one indicator from the home independence construct needed to be freely estimated in the HIN group; one parcel from the social skills construct could only be equated in the HIN and ORT groups and in the INT, SEN, COG, and TRB groups; and one item from the access to general curriculum (accommodations and modifications) construct could only be equated in the INT and COG groups and in the HIN, SEN, ORT, and TRB groups. Therefore, these intercepts were allowed to vary in the structural models. Because of the incredibly small number of parameters that had to be freed, we can conclude that the same constructs can be measured in the same way across groups (Lee, Little, \& Preacher, 2011).

\begin{tabular}{|c|c|c|c|c|c|c|}
\hline Imvariance tests & $x^{2}$ & of & RMSEA & $90 \% \mathrm{Cl}$ & $\mathrm{CFI}$ & NNFI \\
\hline Configural & 22138.9 & 7572 & 0.047 & $0.046-0.048$ & 0.821 & 0.790 \\
\hline Loadings & 23190.5 & 7752 & 0.048 & $0.047-0.048$ & 0.811 & 0.782 \\
\hline Intercepts & 25445.4 & 7932 & 0.050 & $0.050-0.051$ & 0.785 & 0.759 \\
\hline Intercepts (partial) & 25463.7 & 7927 & 0.049 & $0.048=0.050$ & 0.796 & 0.771 \\
\hline
\end{tabular}

Note. RMSEA = root mean square error of approximation; CFI = comparative fit index; NNFI = non-normed fit index.

Differences in Means, Variances, and Correlations (Research Question 3)

After establishing measurement invariance (partial at the intercept level), we tested for latent differences using two-group contrasts as described in the Method section. Because of the large numbers of comparisons, we are unable to present the complete results of each of the two-group contests in tabular form (although they are available on request from the authors). Instead, Tables 4 to $\underline{6}$ provide the statistically significant differences in latent means, variances, or correlations for the disability group pairings. 
Table 4. Significant Mean Level Differences Across Disability Groups for Constructs.

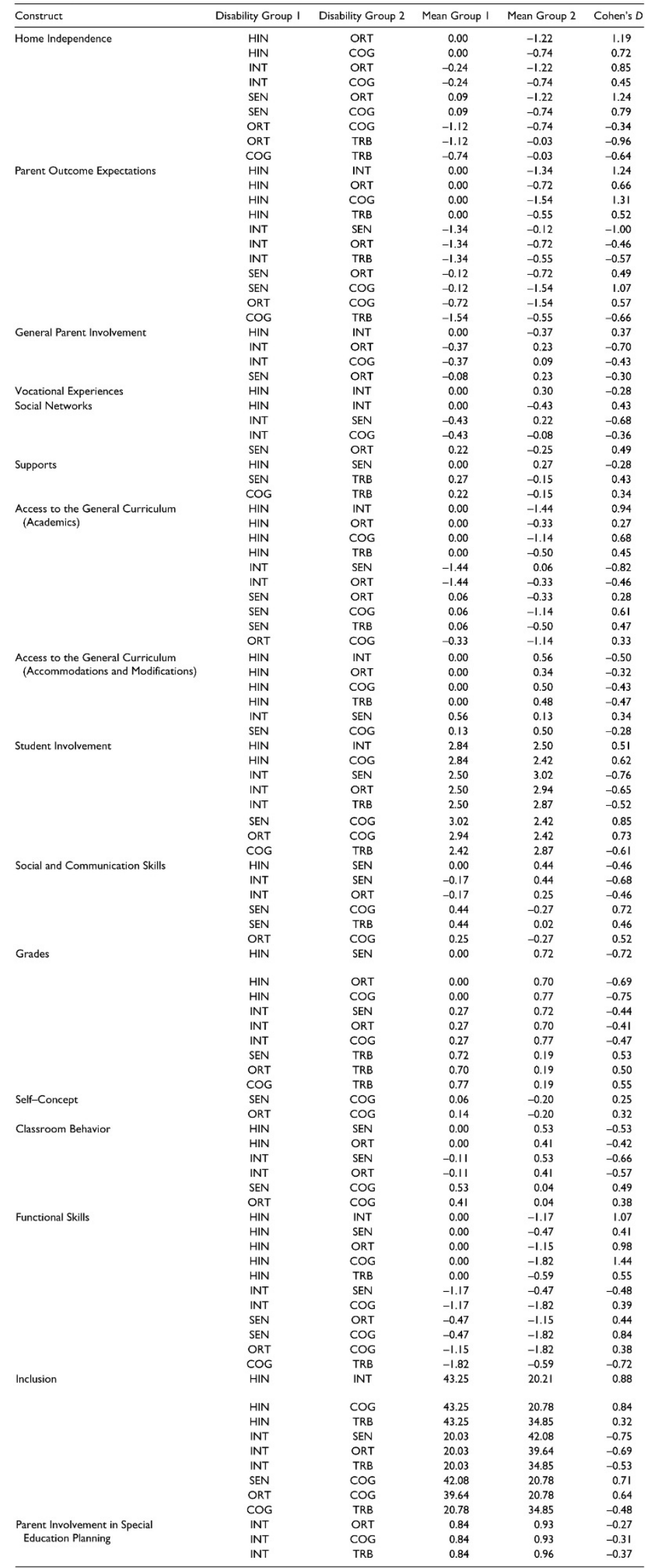

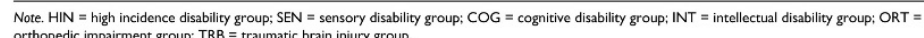
orthopedic impairment group; TRB = traumatic brain injury group. 
Table S. Significant Variance Differences, with Standardized Values and Ratios across Disability Groups

\begin{tabular}{|c|c|c|c|c|c|}
\hline Construct & Disability Group I & Disability Group 2 & Variance Group I & Variance Group 2 & Ratio \\
\hline \multirow{7}{*}{$\begin{array}{l}\text { Parent Outcome } \\
\text { Expectations }\end{array}$} & $\mathrm{HIN}$ & INT & 1.00 & 1.89 & 1.89 \\
\hline & $\mathrm{HIN}$ & ORT & 1.00 & 1.78 & 1.78 \\
\hline & $\mathrm{HIN}$ & COG & 1.00 & 2.32 & 2.32 \\
\hline & $\mathrm{HIN}$ & TRB & 1.00 & 2.06 & 2.06 \\
\hline & INT & COG & 1.89 & 2.32 & 1.22 \\
\hline & SEN & COG & 1.27 & 2.32 & 1.83 \\
\hline & ORT & COG & 1.78 & 2.32 & 1.30 \\
\hline \multirow{3}{*}{$\begin{array}{l}\text { General Parent } \\
\text { Involvement }\end{array}$} & SEN & ORT & 1.24 & 0.62 & 2.02 \\
\hline & ORT & COG & 0.62 & 1.28 & 2.09 \\
\hline & ORT & TRB & 0.62 & 0.99 & 1.61 \\
\hline \multirow{6}{*}{$\begin{array}{l}\text { Vocational } \\
\text { Experiences }\end{array}$} & HIN & INT & 1.00 & 1.84 & 1.84 \\
\hline & INT & SEN & 1.84 & 0.81 & 2.28 \\
\hline & INT & TRB & 1.84 & 0.60 & 3.09 \\
\hline & SEN & ORT & 0.81 & 1.54 & 1.91 \\
\hline & SEN & COG & 0.81 & 1.43 & 1.77 \\
\hline & ORT & TRB & 1.54 & 0.60 & 2.59 \\
\hline \multirow[t]{3}{*}{ Supports } & INT & TRB & 0.85 & 1.52 & 1.79 \\
\hline & INT & TRB & 0.85 & 1.52 & 1.79 \\
\hline & SEN & TRB & 0.79 & 1.52 & 1.93 \\
\hline \multirow{4}{*}{$\begin{array}{l}\text { Access to the } \\
\text { General Curriculum } \\
\text { (Academics) }\end{array}$} & $\mathrm{HIN}$ & INT & 1.00 & 8.33 & 8.33 \\
\hline & $\mathrm{HIN}$ & COG & 1.00 & 7.45 & 7.45 \\
\hline & INT & SEN & 8.33 & 1.01 & 8.29 \\
\hline & SEN & COG & 1.01 & 7.45 & 7.41 \\
\hline \multirow{7}{*}{$\begin{array}{l}\text { Access to the } \\
\text { General Curriculum } \\
\text { (Accommodations } \\
\text { and Modifications) }\end{array}$} & $\mathrm{HIN}$ & INT & 1.00 & 2.17 & 2.17 \\
\hline & $\mathrm{HIN}$ & ORT & 1.00 & 1.67 & 1.67 \\
\hline & $\mathrm{HIN}$ & COG & 1.00 & 2.27 & 2.27 \\
\hline & $\mathrm{HIN}$ & TRB & 1.00 & 1.66 & 1.66 \\
\hline & INT & SEN & 2.17 & 1.32 & 1.64 \\
\hline & INT & ORT & 2.17 & 1.67 & 1.30 \\
\hline & SEN & COG & 1.32 & 2.27 & 1,72 \\
\hline \multirow[t]{2}{*}{ Functional Skills } & $\mathrm{HIN}$ & ORT & 1.00 & 2.85 & 2.85 \\
\hline & $\mathrm{HIN}$ & COG & 1.00 & 3.13 & 3.13 \\
\hline \multirow[t]{3}{*}{ Inclusion } & HIN & SEN & 666.62 & 903.48 & 1.36 \\
\hline & $\mathrm{HIN}$ & ORT & 666.62 & 849,02 & 1.27 \\
\hline & HIN & TRB & 666.62 & 812.31 & 1.22 \\
\hline \multirow{3}{*}{$\begin{array}{l}\text { Parent Imvolvement } \\
\text { in Special Education } \\
\text { Planning }\end{array}$} & INT & ORT & 0.13 & 0.07 & 1.93 \\
\hline & INT & COG & 0.13 & 0.06 & 2.12 \\
\hline & INT & TRB & 0.13 & 0.04 & 3.25 \\
\hline
\end{tabular}

Note. HIN = high inoidence disabilicy group; SEN = sensory dicablicy group; COG = cognilive disabilicy groups INT = intellectual disablity group; ORT = orthopedic impairment group; TRB = traumatic brain injury group. 
Table 6. Significantly Different Correlations and Differences Across Groups.

\begin{tabular}{|c|c|c|c|c|c|}
\hline Correlation & Disability Group I & Disability Group 2 & Group I Corr & Group 2 Corr & Difference \\
\hline \multicolumn{6}{|c|}{ Self-realization-Social Networks } \\
\hline & HIN & SEN & -0.02 & 0.33 & -0.35 \\
\hline \multicolumn{6}{|c|}{ Psychological empowerment-Inclusion } \\
\hline & HIN & SEN & 0.09 & 0.43 & -0.34 \\
\hline & INT & SEN & 0.22 & 0.43 & -0.21 \\
\hline \multicolumn{6}{|c|}{ Home Independence-Parent Outcome Expectations } \\
\hline & HIN & INT & 0.28 & 0.49 & -0.21 \\
\hline & HIN & COG & 0.28 & 0.64 & -0.36 \\
\hline & SEN & COG & 0.37 & 0.64 & -0.27 \\
\hline & ORT & COG & 0.40 & 0.64 & -0.24 \\
\hline \multicolumn{6}{|c|}{ Home Independence-Grades } \\
\hline & HIN & INT & 0.12 & -0.22 & 0.33 \\
\hline & HIN & ORT & 0.12 & -0.17 & 0.29 \\
\hline & HIN & COG & 0.12 & -0.24 & 0.36 \\
\hline Home Indep & e-Functional Skills & & & & \\
\hline & HIN & INT & 0.36 & 0.69 & -0.33 \\
\hline & HIN & ORT & 0.36 & 0.73 & -0.37 \\
\hline & HIN & COG & 0.36 & 0.84 & -0.48 \\
\hline & SEN & COG & 0.57 & 0.84 & -0.26 \\
\hline & COG & TRB & 0.84 & 0.59 & 0.25 \\
\hline Parent Outc & pectations-Access to & eneral Curriculum ( $A$ & nodations and $\mathrm{M}$ & ions) & \\
\hline & HIN & ORT & -0.01 & -0.20 & 0.19 \\
\hline & HIN & TRB & -0.01 & -0.42 & 0.41 \\
\hline & INT & TRB & -0.07 & -0.42 & 0.35 \\
\hline & COG & TRB & -0.06 & -0.42 & 0.36 \\
\hline Parent Outc & pectations-Social an & nunication Skills & & & \\
\hline & HIN & ORT & 0.58 & 0.30 & 0.28 \\
\hline & HIN & COG & 0.58 & 0.30 & 0.28 \\
\hline Parent Outc & pectations-Grades & & & & \\
\hline & HIN & ORT & 0.22 & -0.09 & 0.31 \\
\hline & HIN & COG & 0.22 & -0.26 & 0.48 \\
\hline & SEN & COG & 0.15 & -0.26 & 0.41 \\
\hline Parent Outc & pectations-Self-Con & & & & \\
\hline & HIN & INT & 0.24 & -0.01 & 0.24 \\
\hline & HIN & COG & 0.24 & 0.01 & 0.23 \\
\hline & INT & TRB & -0.01 & 0.38 & -0.38 \\
\hline & COG & TRB & 0.01 & 0.38 & -0.37 \\
\hline Parent Outc & pectations-Parent In & ent in Special Educat & nning & & \\
\hline & HIN & INT & 0.11 & -0.08 & 0.20 \\
\hline & HIN & COG & 0.11 & -0.10 & 0.22 \\
\hline & HIN & TRB & 0.11 & -0.04 & 0.15 \\
\hline General Par & Ivement-Classroom & & & & \\
\hline & HIN & COG & 0.27 & -0.05 & 0.32 \\
\hline Vocational E & ces-Access to the $G$ & Curriculum (Accomn & ons and Modificat & & \\
\hline & HIN & SEN & -0.02 & 0.51 & -0.53 \\
\hline & HIN & ORT & -0.02 & 0.51 & -0.53 \\
\hline Social Netw & rades & & & & \\
\hline & HIN & INT & 0.45 & 0.09 & 0.36 \\
\hline & HIN & COG & 0.45 & 0.03 & 0.42 \\
\hline Access to th & ral Curriculum (Aca & -Access to the Gene & riculum (Accom & ons and Modificat & \\
\hline & SEN & COG & 0.00 & -0.27 & 0.26 \\
\hline & ORT & COG & -0.01 & -0.27 & 0.26 \\
\hline & COG & TRB & -0.27 & 0.11 & -0.38 \\
\hline Access to th & ral Curriculum (Accc & ations and Modificati & cudent Involveme & & \\
\hline & HIN & TRB & 0.03 & -0.45 & 0.48 \\
\hline & INT & TRB & 0.06 & -0.45 & 0.51 \\
\hline & SEN & COG & -0.13 & 0.19 & -0.32 \\
\hline & ORT & COG & -0.07 & 0.19 & -0.26 \\
\hline & COG & TRB & 0.19 & -0.45 & 0.64 \\
\hline Inclusion-So & Communication Ski & & & & \\
\hline & HIN & COG & 0.23 & -0.13 & 0.36 \\
\hline & SEN & COG & 0.21 & -0.13 & 0.34 \\
\hline & ORT & COG & 0.09 & -0.13 & 0.21 \\
\hline Inclusion-Gr & & & & & \\
\hline & HIN & INT & 0.08 & -0.25 & 0.33 \\
\hline & INT & SEN & -0.25 & 0.04 & -0.30 \\
\hline & INT & TRB & -0.25 & 0.02 & -0.27 \\
\hline Inclusion-Fu & | Skills & & & & \\
\hline & HIN & ORT & 0.19 & 0.44 & -0.25 \\
\hline & HIN & COG & 0.19 & 0.48 & -0.29 \\
\hline & INT & ORT & 0.15 & 0.44 & -0.29 \\
\hline & SEN & ORT & 0.19 & 0.44 & -0.25 \\
\hline & SEN & COG & 0.19 & 0.48 & -0.29 \\
\hline Inclusion-Stc & ivolvement & & & & \\
\hline & HIN & ORT & 0.11 & 0.39 & -0.28 \\
\hline & HIN & TRB & 0.11 & 0.43 & -0.32 \\
\hline & SEN & ORT & 0.14 & 0.39 & -0.25 \\
\hline & SEN & TRB & 0.14 & 0.43 & -0.29 \\
\hline & COG & TRB & 0.15 & 0.43 & -0.28 \\
\hline Grades-Stuc & olvement & & & & \\
\hline & HIN & COG & 0.23 & -0.18 & 0.41 \\
\hline & SEN & COG & 0.31 & -0.18 & 0.49 \\
\hline & ORT & COG & 0.14 & -0.18 & 0.32 \\
\hline
\end{tabular}

Note. $\mathrm{HIN}=$ high incidence disability group; $\mathrm{SEN}=$ sensory disability group; $\mathrm{COG}=$ cognitive disability group; INT = intellectual disability group; ORT = orthopedic impairment group; TRB = traumatic brain injury group. 


\section{Means}

In terms of latent means, there were 116 significant differences (40.7\% of total comparisons). Differences were found in all 19 constructs with largest number of significant differences in the parent outcome expectations and functional skills constructs. Generally, students with high incidence disabilities tended to score higher across the majority of constructs, particularly in functional skills, home independence, parent outcome expectations, access to the general education curriculum-academics, social networks, and inclusion. However, students with sensory, orthopedic, and cognitive disabilities tended to score higher on the grades construct, as well as their classroom behavior and access to the general curriculum-accommodations and modifications. Students with cognitive disabilities and orthopedic impairments tended to score lowest in home independence and functional skills, and students with cognitive disabilities and intellectual disability tended to score lowest in parent outcome expectations, student involvement, and inclusion. Table 4 documents each significant mean difference, and provides the unstandardized mean value for each group along with effect sizes. Effect sizes were calculated using the following formula:

$$
\begin{gathered}
d=\frac{\left(\alpha_{1}-\alpha_{2}\right)}{\sqrt{\varphi_{\text {pooled }}}} . \\
\varphi_{\text {pooled }}=\frac{n_{1} \varphi_{1}+n_{2} \varphi_{2}}{\left(n_{1}+n_{2}\right)},
\end{gathered}
$$

where $\alpha$ indicates the latent means, $\phi$ indicates the latent variances, and $n$ indicates the sample sizes for each group.

\section{Variances}

The tests of difference in the latent variances resulted in 47 significant differences across groups (16.5\% of total comparisons) in 12 of the 19 constructs. Differences in variances of the constructs across groups indicate a wider distribution of scores in the group with the higher variance. Generally, students with cognitive disabilities showed the greatest variability perhaps because of the significant diversity of the characteristics of students in these groups. The findings suggest that even though disability may affect how youth experience various contextual factors, within any disability category, there is significant variability in those experiences. Table 5 documents each significant variance difference and provides the unstandardized variance and the ratio of the group difference.

\section{Correlations}

The overall equality test that equated all 171 correlations across all disability groups showed that 20 constructs could not be equated across groups. These 20 correlations resulted in a 
total of 300 comparisons across the six disability groups. Tests of differences across disability groups resulted in 63 significant differences (21\% of total comparisons; see Table 6 ). These differences indicate that disability moderates the relationship between predictor constructs, suggesting the critical importance of considering disability-related factors when attempting to understand the experiences of youth with disabilities. For example, home independence and functional skills were highly correlated for students with intellectual, orthopedic, and cognitive disabilities and less so for students with high incidence disabilities. Further, the relationship between parent outcome expectations and access to accommodations and modifications was stronger for students with cognitive disabilities and traumatic brain injury than it was for students with high incidence disabilities. Finally, the correlation between inclusion and functional skills was most pronounced for students with orthopedic and cognitive disabilities, and the correlation between inclusion and student involvement was most pronounced for students with traumatic brain injury and orthopedic impairments compared to those for other disability groups. Table 6 provides the correlations that were significantly moderated by disability label, including the actual correlation for each group, as well as the difference between groups.

\section{Discussion}

This article used data from NLTS2 to (a) conceptually define and empirically validate student, family, and school constructs, (b) explore the degree to which these constructs could be measured equivalently across disability groups, and (c) explore latent differences in means, variances, and correlations across disability groups. Defining contextual factors and ensuring that they can be measured equivalently are foundational steps that allow for examination of differences in the experiences of youth with disabilities. The present findings suggest that disability label affects the experiences of youth with disabilities in secondary school, although these impacts play out in a complex context, confirming that student, family, and school factors must be comprehensively understood and integrated to understand how to individualize systems of supports to improve experiences and outcomes (Cook \& Odom, 2013).

\section{Defining Contextual Factors (Research Question 1)}

If the field is to adopt a social-ecological model of disability (Schalock et al., 2010; World Health Organization, 2007) and take seriously the tenants of implementation science (Cook \& Odom, 2013), a necessary first step is to determine the best ways to measure and integrate contextual factors. The present analyses (a) identified constructs research suggests affect the secondary school experiences of youth with disabilities and (b) empirically established which constructs can be reliability defined and measured using NLTS2 data. This lays a foundation for examining disability-related differences (Research Questions 2 and 3) and allows for future work attempting to understand and integrate the influence of contextual factors in research and practice, including examination of the degree to which contextual factors in secondary school affect adult outcomes across disability groups.

It is important to note, as future studies such as NLTS2 are designed and conducted, that all but one of the initial 21 conceptual constructs underwent significant empirical modifications during initial CFAs. Interestingly, the only construct that remained as proposed in was the self- 
concept construct of which the items were derived from an existing measure with reliability and validity data, the Student Self-Concept Scale (SSCS; Gresham, 1995). The remaining conceptual constructs required significant revisions, including the narrowing of constructssuch as the conceptual academic skills construct only being represented by items specific to student's grades. Furthermore, because of the lack of relationships between some NLTS2 indicators that seemed conceptually related (e.g., indicators of students involvement in transition planning), single indicator constructs were used to keep certain constructs in the model, but single indicator items provide none of the benefits of generating latent constructs (e.g., improved validity and accuracy of estimated effects). Ultimately, latent constructs can be generated from NLTS2 data, but they perform best when based on scales with established reliability.

\section{Establishing Measurement Equivalence (Research Question 2)}

In addition to examining the degree to which each construct is empirically supported, it is important to examine how they function in an overall model and whether they can be measured equivalently across disability groups. Examining measurement equivalence, particularly across the range of disability groups represented in IDEA, is critical as it is possible that the measurement of contextual factors (i.e., the specific items that define each construct) could be influenced by characteristics associated with disability. Although previous research has established measurement equivalence in a limited number of contextual factors in students with high-incidence disabilities (e.g., inclusion, empowerment; Shogren et al., 2007), researchers have not attempted to explore the measurement equivalence of the range of contextual factors. It is possible that disability characteristics could influence the definition and measurement of certain contextual factors. For example, social and communication skills could be defined differently at the item-level across groups based on different modes of communicating, or home independence could potentially be defined by different indicators based on support needs. We were able to establish partial strong metric invariance, suggesting that despite the need to free a very small number of parameters in the model, the overall latent constructs can be defined in the same way (Lee, Preacher, \& Little, 2011), allowing for analysis of latent, or construct, level differences in student, family, and school factors across disability groups.

\section{Exploring Differences in Means, Variances, and Correlations (Research Question 3)}

After defining the constructs and ensuring that they could be measured equivalently across groups, differences in the actual constructs were examined. Such information, particularly when examined within the context of social-ecological models and the development of frameworks to comprehensively integrate information on contextual factors, has direct implications for future research and practice. Overall, the findings suggest that when comprehensively examining a diverse array of contextual factors, there are complicated relationships and that any factor (e.g., independence, parent involvement) is likely shaped by another student, family, and school factors, and this complexity must be considered in research and practice. For example, mean level differences, such as the finding that students with more significant disabilities tended to score lower on constructs such as home independence, parent outcome expectations, student involvement, access to the general 
education curriculum (academics), social networks, and inclusion confirm, in a nationally representative sample, that students with severe disabilities continue to be less likely to be involved their own educational experiences and be provided appropriate supports for independence and the achievement of adult outcomes. However, establishing that students with orthopedic impairments and cognitive impairments tend to score even lower than other students with severe disabilities in home independence and that students with intellectual disability tend to score lowest in parent outcomes expectations, student involvement, inclusion, and social networks adds to the existing literature on the influence of disability label, as previous literature has typically only compared students with intellectual and learning disabilities (Wehmeyer et al., 2012) or learning disabilities and emotional disturbances (Carter, Lane, Pierson, \& Glaeser, 2006). This underscores the need for additional research on strategies to support students with these labels, as much of the existing research has focused on high-incidence populations (Test et al., 2009).

For students with orthopedic and cognitive disabilities, general parent involvement tended to be higher (although it is important to note that there was still significant variability in each of these constructs highlighting how other student, family, and school characteristics exert influence). This suggests that parents may demonstrate higher levels of involvement, even in general educational activities when their children have severe disabilities. These findings suggest the reciprocal influence of school and family factors, and the need, in practice, to understand the supports that students have available across ecological systems. For example, work is needed to examine the degree to which parent involvement mediates the role between student's school-based experiences and outcomes, as well as research to determine the degree to which parent involvement is influenced by school-based factors. For example, are parents more involved when there are issues with school-based services, or is parent involvement shaped by other factors such as student and family characteristics. The higher level of parent involvement for students with severe disabilities is consistent with other research (Ruef \& Turnbull, 2002; Shogren, 2012), but the results also suggest that students with more severe disabilities do not necessarily receive significantly more supports or vocational or inclusive experiences even if there is greater involvement, nor have greater access to social networks despite research suggesting these areas can be important to positive transition outcomes (Carter et al., 2009; Wehman, 2012). Further, students with intellectual disability, while scoring more adaptively than students with severe disabilities in some domains (e.g., home independence), tended to score the lowest in multiple domains, including parent outcome expectations, parent involvement, social networks, access to the general curriculum-academics, and inclusion suggests a critical need to further address ways to promote high expectations and access to inclusive environments with peers. Further work is needed to decompose the pattern of relationships across ecological systems and the impact of these factors on outcomes.

The pattern of differences in the correlations also confirms the importance of an integrated, comprehensive understanding of contextual factors. While interpreting each and every significant difference presented in Table 6 is not possible, the pattern of findings is indicative of disability moderating the relationship between key student, family, and school constructs. This emphasizes the need to consider disability-related factors in research and practice, although, as noted previously, given the mean and variance differences, disability alone is not the sole 
explanatory factor. Instead, the relationships between constructs must be considered in the complex ecological context. For example, for students with cognitive disabilities and orthopedic impairments, there are stronger relationships between inclusion and functional skills, suggesting that students who have higher functional skills may be more likely to be in inclusive environments or that being inclusive environments may raise perceptions of functional skills. Further, parent outcome expectations showed a stronger relationship with access to accommodations and modifications for students with cognitive disabilities and traumatic brain injuries. These findings suggest that expectations as well as skill level still influence access to inclusive environments and accommodations and modification in these environments, despite the notion that students should not have to "earn" their way into inclusive environments. This finding confirms for this group, in particular, the critical importance of inclusion and access, issues that have been raised by researchers (Lee, Wehmeyer, Palmer, Soukup, \& Little, 2008) and suggests the importance on ongoing efforts to fully integrate schools, providing inclusive, tiered systems of supports for all students (Sailor, 2009). Although given the variability in each of these constructs for this population, it is likely that other factors such as expectations and supports also contribute to the findings. In practice, disability should be one consideration when attempting to understand how student, family, and school factors affect students, but high expectations, inclusion, and student involvement seem to be key issues to consider when attempting to supports students with severe disabilities. Further research is needed, for example, on the role of outcome expectations in moderating the relationship between access and disability label.

Overall, the findings suggest that the tenants of implementation science and the socialecological theory must be integrated into research and practice, and suggest a critical need for tools to assist researchers and practitioners in cataloguing the contextual factors that affect the experiences and outcomes of students so that they can be considered in building a system of support.

\section{Limitations of the Study}

Ultimately, the present analyses, and any secondary data analyses, are limited by the availability and quality of the data available. NLTS2 was designed to primarily include individual survey items. As we have suggested in other work (Shogren, Wehmeyer, Palmer, Rifenbark, \& Little, 2013), generating latent constructs allows us to move beyond simply yes/no indicators (e.g., did you attend your IEP) to include information on the quality of those experiences (e.g., at what level did you participate in your IEP and was it meaningful?). By including items on access and quality, constructs that are more representative of the range of youth experiences and outcomes can be developed. However, unless this is planned (and budgeted for), the only approach available to researchers is to use individual survey items and determine, post hoc, the degree to which they operate as latent constructs. Ultimately, when interpreting the constructs validated in this article, it is important to remember that the constructs were generated post hoc from data collected primarily as individual, stand-alone survey items. While the constructs generated in this analysis show strong fit the data, it is possible that key theoretical elements of the constructs may not be represented because of a lack of available data. Furthermore, different research teams may define constructs in different ways and obtain different findings. Finally, some individuals may be interested in individual 
survey items (e.g., used or not used, included or not included) as their primary outcome of interest, and these items may function well for those analyses. In addition, we used a specific sample of students included in NLTS2 in our analyses (i.e., students who were able to participate in the Direct Assessment items on self-determination) so the results are only generalizable to that population of students.

\section{Implications for Future Research and Practice}

Even with the limitations, the present analyses suggest that it is possible to develop student, family, and school constructs using NLTS2 data and that these constructs can be measured equivalently across disability groups. The latent differences provide insight into the complex interplay of student, family, and school constructs within and across disability groups and suggest that to understand the secondary school experiences of youth with disabilities as well as their post-school outcomes, the complex interaction of these factors must be examined. Future research is needed to decompose the impact of disability (e.g., is it disability-related characteristics, support needs, or attitudes) as well as to further examine specific, significant relationships among student, family, and school constructs. Future research is also needed on the degree to which these constructs predict outcomes, including self-determination and postschool outcomes related to employment, postsecondary education, and independent living. Each of the student, family, and school constructs described in Table 2 has the potential to promote outcomes, but systematic, empirical examinations of the degree to which specific constructs predict outcomes could lead to the identification of key areas to emphasize when working to promote valued outcomes.

The current findings confirm the importance of inclusive opportunities for youth with severe disabilities, as well as a lack of support and social networks for such students. The results also suggest that disability label moderates the relationships between student, family, and school factors and must be one factor considered when designing systems of supports. In practice, the findings suggest the critical role of practitioners developing a comprehensive understanding of the context experienced by each student (e.g., what is the level of parent involvement, access to inclusive experiences, supports, social networks, etc. and how do these factors interact) and work across ecological systems to develop supports that promote positive experiences and outcomes. Future research is needed to examine the contextual factors that affect valued school and post-school outcomes, the degree to which disability group (and other factors) mediate or moderate these relationships, and how to create frameworks and then interventions that, in practice, address the impact of these contextual factors.

\section{Acknowledgements}

The authors would like to thank Christy Nittrouer, Christopher Cormier, Steven Okleshen, and Kim Wolowiec-Fisher for their work in reviewing items for the conceptual constructs, and Renee Cameto and Kathy Valdes for their feedback on the conceptual constructs. 


\section{Authors' Note}

The opinions expressed are those of the authors and do not represent views of the Institute or the U.S. Department of Education.

\section{Editors' Note}

This article has been corrected, per the corrigendum statement in this issue.

\section{Declaration of Conflicting Interests}

The author(s) declared no potential conflicts of interest with respect to the research, authorship, and/or publication of this article.

\section{Funding}

The author(s) disclosed receipt of the following financial support for the research, authorship, and/or publication of this article: The research reported here was supported by the Institute of Education Sciences, U.S. Department of Education, through Grant R324A110040 to the University of Illinois/University of Kansas.

\section{References}

1 Bronfenbrenner, U. (Ed.). (2005). Making human beings human: Bioecological perspectives on human development. Thousand Oaks, CA: SAGE.

2 Carter, E. W., Lane, K. L., Pierson, M. R., Glaeser, B. (2006). Self-determination skills and opportunities of transition-age youth with emotional disturbance and learning disabilities. Exceptional Children, 72, 333-346.

3 Carter, E. W., Trainor, A. A., Cakiroglu, O., Cole, O., Swedeen, B., Ditchman, N., Owens, L. (2009). Exploring school-employer partnerships to expand career development and early work experiences for youth with disabilities. Career Development for Exceptional Individuals, 32, 145-159.

4 Cheung, G. W., Rensvold, R. B. (2002). Evaluating goodness-of-fit indexes for testing measurement invariance. Structural Equation Modeling, 9, 233-255.

5 Cook, B. G., Odom, S. (2013). Evidence-based practices and implementation science in special education. Exceptional Children, 79, 135-144.

6 Gresham, F. M. (1995). Student Self-Concept Scale: Description and relevance to students with emotional and behavioral disorders. Journal of Emotional and Behavioral Disorders, 3, 19-26. doi:10.1177/106342669500300103

7 Lee, J., Little, T. D., Preacher, K. J. (2011). Methodological issues in using structural equation models for testing differential item functioning. In Davidow, E., Schmidt, P., Billiet, J. (Eds.), Cross-cultural data analysis: Methods and applications (pp. 55-84). New York: Routledge.

8 Lee, S. H., Wehmeyer, M. L., Palmer, S. B., Soukup, J. H., Little, T. D. (2008). Selfdetermination and access to the general education curriculum. The Journal of Special Education, 42, 91-107. doi:10.1177/0022466907312354 
9 Little, T. D. (1997). Mean and covariance structures (MACS) analyses of cross-cultural data: Practical and theoretical issues. Multivariate Behavioral Research, 32, 53-76. doi:10.1207/s15327906mbr3201_3

10 Little, T. D. (2013). Longitudinal structural equation modeling. New York, NY: Guilford Press.

11 Little, T. D., Rhemtulla, M., Gibson, K., Schoemann, A. M. (2013). Why the items versus parcels controversy needn't be one. Psychological Methods, 18, 285-300.

12 Muthén, L. K., Muthén, B. O. (1998-2010). Mplus user's guide (6th ed.). Los Angeles, CA: Muthén \& Muthén.

13 Ruef, M. B., Turnbull, A. P. (2002). The perspectives of individuals with cognitive disabilities and/or autism on their lives and their problem behavior. Research and Practice for Persons with Severe Disabilities, 27, 125-140.

14 Sailor, W. (2009). Making RTI work: How smart schools are reforming education through schoolwide response-to-intervention models. San Francisco, CA: Jossey-Bass.

15 Schalock, R. L., Borthwick-Duffy, S., Bradley, V., Buntix, W. H. E., Coulter, D. L., Craig, E. P. M., . . Yeager, M. H.(2010). Intellectual disability: Definition, classification, and systems of support (11th ed.). Washington, DC: American Association on Intellectual and Developmental Disabilities.

16 Shogren, K. A. (2012). Hispanic mothers' perceptions of self-determination. Research and Practice for Persons with Severe Disabilities, 37, 170-184.

17 Shogren, K. A. (in press). A social-ecological analysis of the self-determination literature. Intellectual and Developmental Disabilities.

18 Shogren, K. A., Kennedy, W., Dowsett, C., Little, T. D. (in press). Autonomy, psychological empowerment, and self-realization: Exploring data on self-determination from NLTS2. Exceptional Children.

19 Shogren, K. A., Luckasson, R., Schalock, R. L. (in press). The definition of context and its application in the field of intellectual disability. Journal of Policy and Practice in Intellectual Disabilities.

20 Shogren, K. A., Wehmeyer, M. L., Palmer, S. B., Rifenbark, G. G., Little, T. D. (2013). Relationships between self-determination and postschool outcomes for youth with disabilities. The Journal of Special Education. Advance online publication. doi:10.1177/0022466913489733

21 Shogren, K. A., Wehmeyer, M. L., Palmer, S. B., Soukup, J. H., Little, T. D., Garner, N., Lawrence, M. (2007). Examining individual and ecological predictors of the selfdetermination of students with disabilities. Exceptional Children, 73, 488-509.

22 SRI International. (2000). National Longitudinal Transition Study-2 (NLTS2): Study design, timeline and data collection plan. Menlo Park, CA: Author.

23 Taylor, A. B. (2008). Two new methods of studying the performance of SEM fit indicators (Unpublished doctoral dissertation). Arizona State University, Phoenix. 
24 Test, D. W., Mazzotti, V. L., Mustian, A. L., Fowler, C. H., Kortering, L., Kohler, P. (2009). Evidence-based secondary transition predictors for improving postschool outcomes for students with disabilities. Career Development for Exceptional Individuals, 32, 160181. doi:10.1177/0885728809346960

25 Wehman, P. (2012). Life beyond the classroom: Transition strategies for young people with disabilities (5th ed.). Baltimore, MD: Paul H. Brookes Publishing.

26 Wehmeyer, M. L., Shogren, K. A., Palmer, S. B., Williams-Diehm, K., Little, T. D., Boulton, A. (2012). Impact of the self-determined learning model of instruction on student selfdetermination: A randomized-trial placebo control group study. Exceptional Children, 78, 135-153.

27 World Health Organization. (2007). International classification of functioning, disability and health: Children and youth version. Geneva, Switzerland: Author. 